\title{
Enhanced $A_{1}$ adenosine receptor-induced vascular contractions in mesenteric artery and aorta of in L-NAME mouse model of hypertension.
}

\author{
Vishal R Yadav ${ }^{1}$, Bunyen Teng ${ }^{2}$, and S. Jamal Mustafa, ${ }^{2,}$ \\ ${ }^{1}$ Department of Physiology and Pharmacology, West Virginia University, Morgantown, WV, USA. \\ ${ }^{2}$ Coagulation and Blood Research Task Area, US Army Institute of Surgical Research, San \\ Antonio, TX, USA.
}

\begin{abstract}
L-NAME-induced hypertension is commonly used to study endothelial dysfunction and related vascular effects. It has been reported that genetic deletion of $A_{1}$ adenosine receptor $(A R)$ reduces blood pressure (BP) increases in mice and thus, suggesting the involvement of $A_{1} A R$. Thus, we sought to determine whether $\mathrm{A}_{1} \mathrm{AR}$-induced vascular responses were altered in this mouse model of hypertension. L-NAME $(1 \mathrm{mg} / \mathrm{ml})$ was given in the drinking water for 28 days to mice. The BP was monitored using non-invasive tail-cuff system. Muscle tension studies were performed using DMT for mesenteric arteries (MAs) and organ bath for aorta. Protein expression was analyzed by western blot. Significantly, higher systolic and mean arterial blood pressure was noted in L-NAME mice. In MAs, higher 2-Chloro- $\mathrm{N}^{6}$-cyclopentyladenosine (CCPA, selective $\mathrm{A}_{1} \mathrm{AR}$ agonist) induced contractions in hypertensive mice were observed. This enhanced contraction was inhibited by HET0016 (Cytochrome 450 4A inhibitor, $10 \mu \mathrm{M}, 15 \mathrm{~min}$ ). Contrary, $5^{\prime}$-(N-Ethylcarboxamido) adenosine (NECA, non-selective AR agonist) induced vascular responses were comparable in both groups. Pinacidil ( $\mathrm{K}_{\mathrm{ATP}}$ channel opener) induced relaxation was significantly increased in hypertensive mice. In aorta, CCPA-induced contractions were enhanced and inhibited by HET0016 in hypertensive mice. Notably, NECA-induced contractions in aorta were enhanced in hypertensive mice. Higher expressions of $\mathrm{A}_{1} \mathrm{AR}$ and Cyp4A were noted in MAs of hypertensive mice. In addition, in aorta, higher $\mathrm{A}_{1} \mathrm{AR}$ and comparable Cyp4A levels were observed in hypertensive mice. $\mathrm{A}_{1} \mathrm{AR}$-induced vascular contractions were enhanced in hypertensive mice aorta and MAs. Cyp4A plays a role in altered vascular responses in MAs.
\end{abstract}

\footnotetext{
*Center for Translational Science Institute, West Virginia University, Morgantown, WV, USA. sjmustafa@ hsc.wvu.edu. Authors contributions:

VY and SJM conceived and designed research; VY and BT performed experiments and analyzed data; VY drafted the manuscript; VY, BT and SJM revised and edited the manuscript.

Publisher's Disclaimer: This is a PDF file of an unedited manuscript that has been accepted for publication. As a service to our customers we are providing this early version of the manuscript. The manuscript will undergo copyediting, typesetting, and review of the resulting proof before it is published in its final citable form. Please note that during the production process errors may be discovered which could affect the content, and all legal disclaimers that apply to the journal pertain.

Disclosures

None.

Conflicts of interest:

The authors declare no conflicts of interest.
} 


\section{Keywords}

L-NAME hypertension; $A_{1}$ AR; aorta; MAs; Cyp4A

\section{Introduction}

Hypertension, characterized by high blood pressure (BP) is involved in various cardiovascular-related diseases. Endothelial dysfunction related to reducing NO levels in the circulation is an important contributing factor responsible for hypertension (Konishi and $\mathrm{Su}$, 1983; Laughlin et al., 2012; Luscher et al., 1988; Nguyen Dinh Cat and Touyz, 2011; Tian et al., 2011). L-NAME, a non-specific NOS inhibitor, down regulates endothelial nitric oxide synthase (eNOS) protein expression and leads to depletion of plasma nitric oxide (NO). LNAME pre-treatment causes systemic vasoconstriction, increased vascular resistance and high BP (Berkban et al., 2015; Nishijima et al., 2014; Paulis et al., 2008). Since, we were interested to study the role of NO and BP regulation and its relationship to vascular ARs, we chose L-NAME model of hypertension for this study.

Adenosine is an important metabolite which regulates local blood flow by controlling vascular tone through activating four subtypes of adenosine receptors (ARs). These ARs are G-protein coupled receptors (GPCRs) namely $A_{1}, A_{2 A}, A_{2 B}$, and $A_{3} \cdot A_{1}$ and $A_{3} A R$ activation cause vascular contraction, while $\mathrm{A}_{2 \mathrm{~A}}$ and $\mathrm{A}_{2 \mathrm{~B}} \mathrm{AR}$ stimulation produces vascular relaxation(Hein et al., 2013; Jacobson and Gao, 2006; Mubagwa and Flameng, 2001; Mubagwa et al., 1996; Ohisalo, 1987; Olanrewaju and Mustafa, 2000; Olanrewaju et al.,

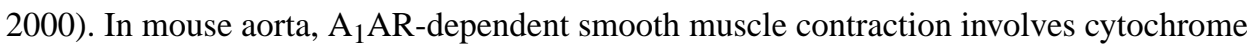
P450 epoxygenase type 4A (Cyp4A), protein kinase C-a, and mitogen-activated protein kinases, mainly p44/42 MAPK(Ansari et al., 2009; Kunduri et al., 2013a; Kunduri et al., 2013b; Sanjani et al., 2011). Notably, A AR-induced vascular contractions were endothelium-dependent in mouse aorta (Nayeem et al., 2008; Ponnoth et al., 2012b). A ARdependent contraction occurs through the generation of thromboxane B2 by cyclooxygenases- 1 that requires the presence of intact endothelium in mouse aorta (Ansari et al., 2007). In mouse MAs, $A_{1} A R$ mediates contraction while the $A_{2 B} A R$ mediates relaxation (Teng et al., 2013). A AR dependent vascular contractions involve activation of Cyp4A, which was dependent on the presence of intact endothelium. Moreover, non-selective AR (such as, NECA)-induced vascular relaxations were partly dependent on endothelium and $\mathrm{K}_{\mathrm{ATP}}$ channel activity (Yadav et al., 2015). Thus, endothelium plays an important role in ARs induced vascular responses.

Reportedly, angiotensin II stimulation-enhanced $\mathrm{A}_{1} \mathrm{AR}$-induced vascular contractions in mouse MAs (Yadav et al., 2015). Interestingly, in L-NAME-induced hypertensive mice, genetic deletion of $\mathrm{A}_{1} \mathrm{AR}\left(\mathrm{A}_{1} \mathrm{AR}^{-/-}\right)$attenuates renal afferent arteriolar contraction and hypertension (Gao et al., 2011). Genetic deletion of $A_{1}$ AR protected L-NAME and ANG IIinduced oxidative stress in arterioles ${ }^{25}$. Furthermore, arteriolar contractions to ANG II were lower in $\mathrm{A}_{1} \mathrm{AR}$ KO mice of L-NAME induced hypertensive mice (Gao et al., 2011). Notably, eNOS expression was lower in $\mathrm{A}_{1} \mathrm{AR}^{-/-}$mice renal afferent arterioles. Suggesting $\mathrm{A}_{1} \mathrm{AR}$ may regulate eNOS expression (Gao et al., 2011). In $\mathrm{A}_{1} \mathrm{AR}^{-/-}$mice, we reported that $\mathrm{NO}$ 
was not involved in enhanced coronary reactive hyperemia (Zhou et al., 2015a). Suggesting $\mathrm{A}_{1} \mathrm{AR}$ may negatively regulate coronary reactive hyperemia. Thus, $\mathrm{A}_{1} \mathrm{AR}$ may regulate vascular tone in L-NAME induced hypertension.

We sought to determine whether AR-dependent vascular responses (including its signaling through $\mathrm{K}_{\mathrm{ATP}}$ channels) were altered in L-NAME induced hypertension in mice.

\section{Materials and Methods}

\subsection{Animals}

Male (C57 BL/6 background) mice of 14-17 weeks age were used in the present study. All animal care and experimentation protocols were approved and carried out in accordance with the West Virginia University Institutional Animal Care and Use Committee and were in accordance with the principles and guidelines of the NIH's Guide for the Care and Use of Laboratory Animals. Our animal facility is AAALAC approved.

\subsection{Pharmacological agents and antibodies}

5 '-(N-ethylcarboxamido) adenosine (NECA) and 2-chloro-N cyclopentyladenosine (CCPA) were purchased from Tocris Biosciences (Minneapolis, MN). Phenylephrine (PE), acetyl choline (ACh), HET0016 and all other chemicals were purchased from Sigma-Aldrich. Antibodies for CYP4A (sc-271983), eNOS (sc-654) and actin (sc-47778) were purchased from Santa Cruz Biotechnology, Santa Cruz, CA. The $A_{1}$ AR antibody was purchased from Sigma-Aldrich.

\subsection{L-NAME model and Blood pressure measurements}

Mice were given L-NAME in drinking water at $1 \mathrm{mg} / \mathrm{ml}$ concentration for 28 days. The blood pressure was measured throughout the 28 days protocol using non-invasive tail cuff (CODA-8) method obtained from Kent Scientific (Daugherty et al., 2009) as per manufacturers protocol. Data are presented as both mean arterial blood pressure (MABP) and systolic blood pressure (SABP). Average weight of the mice at the start of the protocol was (in gm) $28.5 \pm 0.8(\mathrm{n}=9)$ and $28.1 \pm 0.8(\mathrm{n}=10)$ in control and L-NAME groups, respectively. At the end of the protocol average weight of the mice in control group was significantly increased to $30.9 \pm 1.1$. On the other hand, weight of the mice in L-NAME group was comparable between start and end of the protocol. Drinking water to control and L-NAME groups was provided ad libitum. On an average control mice consumed $\sim 16 \mathrm{ml} /$ week whereas, L-NAME mice consumed $\sim 6 \mathrm{ml} /$ week water.

\subsection{Tissue preparation and isometric force measurement}

Mice were euthanized by anesthesia with pentobarbital sodium ( $65 \mathrm{mg} / \mathrm{kg}$ i.p.). By thoracotomy aorta was dissected out and the mouse mesentery with intestines were carefully excised and placed in cold oxygenated and (5\% CO2 and 95\% O2) modified KrebsHenseleit physiological salt solution (PSS, in $\mathrm{mM}$ : $\mathrm{NaCl} 120, \mathrm{NaHCO} 325, \mathrm{KCl} 4.7$, KH2PO4 1.2, $\mathrm{CaCl} 2$ 1.8, MgSO4 1.2, glucose 15, and EDTA 0.05, pH 7.4). 
The aorta was subjected to isometric force measurement using isolated organ bath method as described from our laboratory (Ponnoth et al., 2012a; Zhou et al., 2015b). A preload of $1 \mathrm{gm}$ was given to isolated aorta rings during the equilibration period. A DMT (Danish Myo Technology A/S, Aarhus, Denmark) myograph was used to perform muscle tension measurements in MAs as described previously (Yadav et al., 2016; Yadav et al., 2015). Second order MA rings (3-5 mm long, $75-150 \mu \mathrm{m}$ in diameter) were mounted on the DMT myograph with continuous oxygenation at $37^{\circ} \mathrm{C}$. A preload of $300 \mathrm{mg}$ was applied to the MAs during the equilibration period of $90 \mathrm{~min}$. In both vascular tissues, the viability of the arteries and the presence of endothelium was tested using potassium chloride $(\mathrm{KCl}, 50 \mathrm{mM})$ and acetylcholine (ACh $1 \mu \mathrm{M}$ ), respectively. Concentration-response curves (CRCs) were obtained in tissues initially contracted with phenylephrine (PE $1 \mu \mathrm{M})$. The muscle tension generated in each CRCs was plotted and normalized to the corresponding \% contraction to the basal tension obtained using PE $(1 \mu \mathrm{M})$. Intact endothelium was present in all of our muscle tension measurement experiments.

\subsection{Western blotting}

Western blot analysis was performed as described previously (Ponnoth et al., 2012a; Ponnoth et al., 2012b; Yadav et al., 2016; Yadav et al., 2015). Briefly, aorta and MAs isolated from control and L-NAME mice were homogenized with $125 \mu \mathrm{l}$ of RIPA Lysis and Extraction Buffer (Peirce \#89901 mixed with $1 \mathrm{mM}$ of Na3VO4, $1 \mathrm{mg} / \mathrm{ml}$ of leupeptin and $1 \mathrm{mM} \mathrm{NaF}$ ), vortexed, and centrifuged for $10 \mathrm{~min}$ at $10,000 \mathrm{~g}$ at $4{ }^{\circ} \mathrm{C}$. Protein was estimated by Lowry's method using Bio-Rad Laboratories protein assay concentrate. Samples (5-15 $\mu \mathrm{g}$ of total protein) were loaded into slab gels ( $10 \%$ acrylamide; $1.5 \mathrm{~mm}$ thick), separated by sodium dodecyl sulfate polyacrylamide gel electrophoresis, and transferred to nitrocellulose membranes (Hybond-ECL). Membranes were blocked with 5\% nonfat dry milk for 45 min and incubated overnight with primary antibodies. All primary antibody dilutions were 1:1000. Membranes were developed using enhanced chemiluminescence (Amersham BioSciences) and GE Amersham Imager 600. Densitometry analysis was performed using Multi Guage V3.0 software. The data obtained were normalized to the intensity of the actin band and presented as the normalized ratio (\% change) of the target protein to control protein expression.

\subsection{Statistical analysis}

All the data are presented as a mean \pm standard error. Data in CRCs were analyzed between groups at the same concentrations. Comparisons between two groups were made using Student's t-test. Two way ANOVA, followed by Bonferroni post-tests, was used to compare means of different CRCs. Values at $\mathrm{P}<0.05$ were considered statistically significant. In all data, " $n$ " represents the number of animals used to perform experiments.

\section{Results}

\subsection{Blood pressure response in L-NAME-induced hypertension model}

L-NAME $(1 \mathrm{mg} / \mathrm{ml})$ was given to the mice in drinking water for 28 days period. The blood pressure responses were regularly monitored throughout the 28 days model period. As shown in Fig. 1, systolic and mean arterial blood pressure (SABP and MABP) was higher in 
L-NAME mice. The MABP of L-NAME mice were higher from day 3 onwards and stayed significantly higher throughout the 28 day period. The MABP observed at day 0 was $(\mathrm{mmHg})$ was $83.9 \pm 2.3$ in control and $86.4 \pm 2.7$ in L-NAME group $(\mathrm{P}>0.05)$. At the end of our hypertension model (day 28), MABP was $86.6 \pm 2.5$ and 112.2 \pm 2.8 in control and LNAME group, respectively $(\mathrm{P}<0.05)$. Whereas, $\mathrm{SABP}$ (Fig. 1A) in control group at day 28 was $110.3 \pm 1.9$ and in L-NAME group was $134.9 \pm 3.1(\mathrm{P}<0.05)$.

\subsection{Vascular responses in L-NAME hypertensive mice}

In L-NAME hypertensive and control mice, we measured vascular responses in MAs and aorta. In MAs of L-NAME hypertensive mice, ACh $(1 \mu \mathrm{M})$-induced relaxation was significantly reduced (\% to PE) to $-93.5 \pm 1.4(\mathrm{n}=9)$ compared to $-98.5 \pm 0.2(\mathrm{n}=9)$ in control. Importantly, PE $(1 \mu \mathrm{M})$-induced responses were significantly reduced in L-NAME group from (mg) $278.8 \pm 32.8(\mathrm{n}=9)$ compared to $492.1 \pm 33.8(\mathrm{n}=9)$ in control $(\mathrm{p}<0.05)$. In addition, $\mathrm{KCl}$-induced vascular contractions were comparable in MAs. The contractions observed were $369.7 \pm 18.1(\mathrm{n}=9)$ in control and $336.1 \pm 21.5(\mathrm{n}=9)$ in L-NAME group.

In aorta of L-NAME hypertensive mice, $\mathrm{ACh}$ induced relaxation and $\mathrm{KCl}$-induced contractions were comparable to control. $\mathrm{KCl}$ induced contractions observed were 312.6 \pm 23.7 and $297.0 \pm 19.0$ ( $\mathrm{n}=9$ each) in control and L-NAME mouse aorta. ACh induced relaxation observed in aorta were (\% to PE) $-55.6 \pm 2.7$ and $-59.1 \pm 4.6(n=9)$. Importantly, PE $(1 \mu \mathrm{M})$-induced vascular contractions were significantly reduced in aorta of L-NAME hypertensive mice. The contractions observed were $(\mathrm{mg}) 169.5 \pm 1.6(\mathrm{n}=9)$ and $113.5 \pm 2.0$ $(\mathrm{n}=9)$ in control and L-NAME hypertensive mice $(\mathrm{P}<0.05)$, respectively. Thus, vascular responses in both aorta and MAs were altered in L-NAME hypertensive mice.

\subsection{Role of $A_{1} A R$ in regulating vascular tone in MAs and aorta of L-NAME-induced hypertensive mice}

To study the role of ARs in regulating vascular tone in L-NAME induced hypertension model, we performed CCPA (selective AR $\mathrm{A}_{1}$ agonist) and NECA (non-selective AR agonist) induced CRCs in MAs and aorta of control and L-NAME mice. As shown in the Fig. 2A, CCPA induced contractions were significantly higher in MAs of L-NAME mice. Particularly, CCPA at $100 \mathrm{nM}$ caused contraction (\% to PE contraction) of $24.9 \pm 14.1$ and $89.2 \pm 27.4$ in control and L-NAME mice MAs, respectively (P < 0.05). HET0016 (Cyp4A inhibitor, $10 \mu \mathrm{M}$ ), pretreatment significantly attenuated hypercontractility observed in MAs of L-NAME mice (Fig. 2A) but had no effect in control tissues. Further, we found that NECA-induced contractions were comparable in control and L-NAME mice MAs (Fig. 2B). Pinacidil ( $\mathrm{K}_{\mathrm{ATP}}$ channel opener)-induced vascular relaxation responses were significantly higher in L-NAME mice MAs (Fig. 2C). At $1 \mu \mathrm{M}$, relaxation observed to pinacidil in MAs was $-51.7 \pm 9.8$ and $-76.3 \pm 5.9$ in control and L-NAME, respectively $(\mathrm{P}<0.05)$.

In aorta of L-NAME hypertensive mice, significantly enhanced contraction to CCPA was observed (Fig. 3A). At $1 \mu \mathrm{M} \mathrm{CCPA}$, contractions were $78.9 \pm 5.9$ and $101.2 \pm 8.9$ in control and L-NAME mice, respectively (Fig. 3A, P < 0.05). Notably, HET0016 preincubation significantly reduced CCPA induced contractions in control as well as L-NAME mouse aorta (Fig. 3A). Furthermore, NECA-induced contractions were altered in aorta of L-NAME mice 
(Fig. 3B). Pinacidil-induced relaxation responses were comparable in control and L-NAME mice (Fig. $3 \mathrm{C}$ ). Thus, suggesting that $\mathrm{A}_{1} \mathrm{AR}$ plays a role in enhanced vascular contraction, which was mediated by Cyp4A in MAs and aorta of L-NAME mice.

\subsection{Expression profile of $A_{1} A R$, eNOS and Cyp4A}

To test whether changes in the expression of $A_{1} A R$ and Cyp4A accounts for the change in vascular responses in L-NAME hypertensive mice, we performed western blot analysis. Our data revealed significantly higher expression of $\mathrm{A}_{1} \mathrm{AR}$ and Cyp4A (Fig. 4 A-C) in MAs of L-NAME mice. Furthermore, in aorta of L-NAME mice, higher $\mathrm{A}_{1} \mathrm{AR}$ and unchanged Cyp4A expression levels were observed compared to control (Fig. 5 A-C). Notably, eNOS expression was comparable in MAs and aorta of control and L-NAME mice. The eNOS expression was $100.0 \pm 13.5(\mathrm{n}=6)$ and $81.1 \pm 19.2(\mathrm{n}=7)$ in MAs of control and L-NAME mice (Fig. 4D-E), respectively. In aorta of control mice, eNOS expression observed was $100.0 \pm 13.9(\mathrm{n}=6)$ and in L-NAME mice was $70.5 \pm 11.6(\mathrm{n}=6$, Fig. 5D-E).

Thus, indicating that higher expression of $\mathrm{A}_{1} \mathrm{AR}$ and Cyp4A play roles in higher contractile responses observed in L-NAME-induced hypertensive mice.

\section{Discussion}

The present study was aimed to determine whether ARs induced vascular responses were altered in L-NAME model of hypertension in mice. Important findings of this study were as follows.: 1) $A_{1} A R$ induced contractile responses were higher in aorta and MAs; 2) $A_{1} A R$ induced contractile responses were dependent on Cyp4A;3) Higher expression of $A_{1} A R$ and Cyp4A was observed in MAs; 4) Higher $\mathrm{A}_{1} \mathrm{AR}$ and comparable Cyp4A expression was noted in aorta; 5) Pinacidil induced relaxation was higher in MAs; and finally, 6) NECAinduced vascular contractions were higher in aorta. Overall, our data revealed an important role of $A_{1} A R$ in regulating vascular tone in L-NAME model of hypertension in mice.

The endothelium is an important regulator of vascular tone by releasing NO, prostacyclin, and endothelium-derived hyperpolarizing factors (Edwards et al., 2010). Endothelial dysfunction characterized by reduced bioavailability of vascular dilating and increased contracting agents is present in hypertension (Konishi and Su, 1983; Laughlin et al., 2012; Luscher et al., 1988; Nguyen Dinh Cat and Touyz, 2011; Tian et al., 2011). L-NAME, an eNOS inhibitor, reduces NO bioavailability thereby increases systemic vascular resistance leading to high BP (Berkban et al., 2015; Nishijima et al., 2014; Paulis et al., 2008). As expected, we found that chronic administration of L-NAME increased SABP and MABP in mice (Fig. 1), making mice hypertensive. Further, our vascular response analysis data revealed that in MAs, PE-induced contraction and $\mathrm{ACh}$ induced relaxation was reduced in LNAME hypertensive mice. In aorta, ACh induced relaxation was comparable and PEinduced contractions were significantly reduced in L-NAME hypertensive mice. KClinduced contractions were comparable in MAs and aorta. Recently, in L-NAME hypertensive rat aorta, significantly reduced ACh-induced relaxation and higher PE-induced contractions were noted (Prawez et al., 2016). Also, in aorta of L-NAME mice, ACh induced relaxation was reduced (Nagano et al., 2013). Importantly, a decrease in eNOS, phosphorylated eNOS, and NO concentrations were reported in L-NAME hypertensive rat 
ventricles and aorta (Sheng et al., 2017; Wang et al., 2017). In a study of $\mathrm{N}_{\varpi}$-Nitro-Larginine (L-NNA) induced hypertensive rats, PE-induced contractions were comparable in aorta and MAs (Kanagy, 1997). Thus, there are discrepancies in the PE and ACh induced vascular responses in L-NAME (or L-NNA) induced hypertensive rats and mice. Our data showed that ACh induced relaxation was partially but significantly reduced in L-NAME MAs and was comparable in aorta. In our MA preparations, we observed 93-97\% (maximal) relaxation and on the other hand, only $\sim 55-59 \%$ relaxation in aorta in response to ACh in both groups. Notably, comparable eNOS expressions were observed in MAs (Fig. 4D-E) and aorta (Fig. 5D-E) of L-NAME mice which was opposite to other reports (Sheng et al., 2017; Wang et al., 2017). This possibly is likely due to 28 days exposure to L-NAME which, was enough to lower eNOS expression (not significant) in our study. This would suggest that a longer exposure to L-NAME might result in a significant change in eNOS expression. Also, measurering NO bioavailability and phospohorylated -eNOS may reveal further shed light in our study. However, our BP responses in L-NAME hypertensive mice were in agreement with other reports (Berkban et al., 2015; Gao et al., 2011; Nishijima et al., 2014; Paulis et al., 2008). Reduced a-adrenergic receptor-induced responses may occur to compensate for higher BP responses by reducing expression levels of a-1 adrenergic receptors. This claim needs to be investigated in our L-NAME model of hypertension in mice.

Previously, it was reported that genetic deletion of $\mathrm{A}_{1} \mathrm{AR}$ attenuated blood pressure responses in L-NAME induced hypertension mice (Gao et al., 2011). These authors showed that the absence of $\mathrm{A}_{1} \mathrm{AR}$ reduced ANG II-induced contractions and reactive oxygen species generation in renal afferent arterioles obtained from L-NAME hypertensive mice. Among, all 4 ARs subtype, $A_{1}$ and $A_{3}$ AR cause contractions of arteries (Hein et al., 2013; Jacobson and Gao, 2006; Mubagwa and Flameng, 2001; Mubagwa et al., 1996; Ohisalo, 1987; Olanrewaju and Mustafa, 2000; Olanrewaju et al., 2000). In aorta, $A_{1}$ is the major AR (Kunduri et al., 2013a; Kunduri et al., 2013b; Nayeem et al., 2008; Ponnoth et al., 2012a; Pradhan et al., 2015); whereas in MAs, $A_{1}$ is the only AR that regulates contraction (Teng et al., 2013; Yadav et al., 2015). Also, stimulation of $A_{1} A R$ inhibits Bk channels thereby inhibits relaxation in aortic smooth muscle cells (Kunduri et al., 2013a). Thus, a possible important role of inhibiting relaxation through $\mathrm{A}_{1} \mathrm{AR}$ exists in L-NAME hypertensive mice. We investigated this possibility in this study. We investigated whether ARs dependent responses were altered in MAs and aorta of L-NAME hypertensive mice. Our data revealed enhanced $\mathrm{A}_{1} \mathrm{AR}$-induced (with $\mathrm{A}_{1}$ selective agonist) contractile responses in MAs (Fig. 2A) and aorta (Fig. 3A) of hypertensive mice. In MAs, AR agonist-induced responses were comparable (Fig. 2B). In mouse MAs, $\mathrm{A}_{2 \mathrm{~B}} \mathrm{AR}$ mediates vasodilation (Teng et al., 2013; Yadav et al., 2015) which were partly dependent on $\mathrm{K}_{\mathrm{ATP}}$ channel activity (Yadav et al., 2015). In the present report, we found that $\mathrm{K}_{\mathrm{ATP}}$ channel (pinacidil) dependent relaxation of MAs were significantly higher (Fig. 2C) in hypertensive mice. It is highly likely, that $\mathrm{A}_{2 \mathrm{~B}} \mathrm{AR}$ expression may have increased in MAs. Thus, AR-induced vascular contraction and relaxation may negate each other thereby producing comparable ARs induced responses in MAs. Contrary, in aorta of hypertensive mice, AR-induced vascular relaxation was reduced whereas higher contraction was observed (Fig. 3B). In mouse aorta, $\mathrm{A}_{2 \mathrm{~A}}$ (major) and $\mathrm{A}_{2 \mathrm{~B}}$ $\mathrm{AR}$ (partly) cause vascular relaxation, while $\mathrm{A}_{2 \mathrm{~A}} \mathrm{AR}$ dependent vascular relaxation involves 
activation of $\mathrm{K}_{\mathrm{ATP}}$ channels (Ponnoth et al., 2012b; Sharifi-Sanjani et al., 2013; Zhou et al., 2013). In mouse coronary artery, $A_{2 A} A R$ induced relaxation was partially mediated by Nox2-derived hydrogen peroxide (Zhou et al., 2015a). In aorta of high salt fed mice, $A_{2 A} A R$ induced vascular relaxation involves EETs, PPAR $\gamma$, and $\mathrm{K}_{\mathrm{ATP}}$ channels (Pradhan et al., 2015). In our study, we found that $\mathrm{K}_{\mathrm{ATP}}$ channel induced responses were comparable in aorta (Fig. 3C). Thus, various ARs dependent relaxation pathways exist in aorta which may be affected in L-NAME induced hypertensive mice contributing towards high BP.

$\mathrm{A}_{1} \mathrm{AR}$-induced contractions in MAs and aorta were mediated by the activity of Cyp4A (Jacobson and Gao, 2006; Sanjani et al., 2011; Yadav et al., 2016; Zhou et al., 2015a). Likely, higher $\mathrm{A}_{1} \mathrm{AR}$-induced contractions involve Cyp4A in L-NAME hypertensive mice. As expected, we found Cyp4A dependent higher contractions in L-NAME hypertensive mice MAs (Fig. 2A). Furthermore, in aorta, Cyp4A was involved in the higher contractile responses in L-NAME hypertensive mice (Fig. 3A). Importantly, in control aorta, the $\mathrm{A}_{1}$ ARinduced contraction was dependent on Cyp4A (Fig. 3A). Thus, our data indicated that Cyp4A mediates $\mathrm{A}_{1} \mathrm{AR}$-induced contractions in MAs and aorta of L-NAME hypertensive mice. In agreement with our functional data, our expression analysis revealed that $A_{1} A R$ and Cyp4A are higher in L-NAME hypertensive mice MAs (Fig. 4A-C). In aorta, higher $\mathrm{A}_{1} \mathrm{AR}$ and comparable Cyp4A were observed in L-NAME hypertensive mice (Fig. 5 A-C). Recently, increase in 20-HETE (a product of Cyp4A activity) levels in the resistance arteries of L-NAME hypertensive rats was reported (Özen et al., 2017). Furthermore, Cyp4A inhibition attenuated the increase in BP in L-NAME hypertensive rats. Notably, Cyp4A inhibition improved vascular relaxation and contraction responses in the conduit and resistance arteries (Özen et al., 2017). Thus, indicating that in our study, Cyp4A downstream of $\mathrm{A}_{1} \mathrm{AR}$ may be involved in L-NAME induced hypertensive mice. Also, higher expression and contractions of $\mathrm{A}_{1} \mathrm{AR}$ in MAs and aorta contributes towards high blood pressure in LNAME hypertensive mice.

\section{Conclusion}

Our study revealed the important role of $\mathrm{A}_{1} \mathrm{AR}$ in L-NAME induced hypertensive mice. We found an enhanced $A_{1} A R$ induced vascular contractions in MAs and aorta of L-NAME hypertensive. Involvement of Cyp4A, a downstream signaling molecule of $\mathrm{A}_{1} \mathrm{AR}$ contraction pathway enhances vascular reactivity significantly in the present study. Importantly, our data revealed that AR-dependent relaxation was inhibited in aorta. Thus, a future study aiming towards investigating changes in the $\mathrm{A}_{2 \mathrm{~A}}$ and $\mathrm{A}_{2 \mathrm{~B}}$ dependent signaling may unveil the complete role of ARs in L-NAME induced hypertension.

\section{Acknowledgements}

This study was supported by National Institutes of Health grants HL027339 (SJM) and U54GM104942 (Sally Hodder).

\section{References}

Ansari HR, Nadeem A, Tilley SL, Mustafa SJ, 2007 Involvement of COX-1 in A3 adenosine receptormediated contraction through endothelium in mice aorta. Am J Physiol Heart Circ Physiol 293, H3448-3455. [PubMed: 17921329] 
Ansari HR, Teng B, Nadeem A, Roush KP, Martin KH, Schnermann J, Mustafa SJ, 2009 A(1) adenosine receptor-mediated PKC and p42/p44 MAPK signaling in mouse coronary artery smooth muscle cells. Am J Physiol Heart Circ Physiol 297, H1032-1039. [PubMed: 19592614]

Berkban T, Boonprom P, Bunbupha S, Welbat JU, Kukongviriyapan U, Kukongviriyapan V, Pakdeechote P, Prachaney P, 2015 Ellagic Acid Prevents L-NAME-Induced Hypertension via Restoration of eNOS and p47phox Expression in Rats. Nutrients 7, 5265-5280. [PubMed: 26133972]

Daugherty A, Rateri D, Hong L, Balakrishnan A, 2009 Measuring blood pressure in mice using volume pressure recording, a tail-cuff method. J Vis Exp

Edwards G, Feletou M, Weston AH, 2010 Endothelium-derived hyperpolarising factors and associated pathways: a synopsis. Pflugers Archiv : European journal of physiology 459, 863-879. [PubMed: 20383718]

Gao X, Patzak A, Sendeski M, Scheffer PG, Teerlink T, Sallstrom J, Fredholm BB, Persson AE, Carlstrom M, 2011 Adenosine A(1)-receptor deficiency diminishes afferent arteriolar and blood pressure responses during nitric oxide inhibition and angiotensin II treatment. Am J Physiol Regul Integr Comp Physiol 301, R1669-1681. [PubMed: 21975649]

Hein TW, Xu W, Ren Y, Kuo L, 2013 Cellular signalling pathways mediating dilation of porcine pial arterioles to adenosine A(2)A receptor activation. Cardiovasc Res 99, 156-163. [PubMed: 23539502]

Jacobson KA, Gao ZG, 2006 Adenosine receptors as therapeutic targets. Nat Rev Drug Discov 5, 247264. [PubMed: 16518376]

Kanagy NL, 1997 Increased vascular responsiveness to alpha 2-adrenergic stimulation during NOS inhibition-induced hypertension. Am J Physiol 273, H2756-2764. [PubMed: 9435612]

Konishi M, Su C, 1983 Role of endothelium in dilator responses of spontaneously hypertensive rat arteries. Hypertension 5, 881-886. [PubMed: 6654451]

Kunduri S, Dick G, Nayeem M, Mustafa S, 2013a Adenosine A receptor signaling inhibits BK channels through a PKCalpha-dependent mechanism in mouse aortic smooth muscle. Physiol Rep 1.

Kunduri SS, Mustafa SJ, Ponnoth DS, Dick GM, Nayeem MA, 2013b Adenosine A1 receptors link to smooth muscle contraction via CYP4a, protein kinase C-alpha, and ERK1/2. J Cardiovasc Pharmacol 62, 78-83. [PubMed: 23519140]

Laughlin MH, Davis MJ, Secher NH, van Lieshout JJ, Arce-Esquivel AA, Simmons GH, Bender SB, Padilla J, Bache RJ, Merkus D, Duncker DJ, 2012 Peripheral circulation. Comprehensive Physiology 2, 321-447. [PubMed: 23728977]

Luscher TF, Diederich D, Weber E, Vanhoutte PM, Buhler FR, 1988 Endothelium-dependent responses in carotid and renal arteries of normotensive and hypertensive rats. Hypertension 11, 573-578. [PubMed: 3260580]

Mubagwa K, Flameng W, 2001 Adenosine, adenosine receptors and myocardial protection: an updated overview. Cardiovasc.Res 52, 25-39. [PubMed: 11557231]

Mubagwa K, Mullane K, Flameng W, 1996 Role of adenosine in the heart and circulation. Cardiovascular Research 32, 797-813. [PubMed: 8944810]

Nagano K, Ishida J, Unno M, Matsukura T, Fukamizu A, 2013 Apelin elevates blood pressure in ICR mice with LNAMEinduced endothelial dysfunction. Molecular medicine reports 7, 1371-1375. [PubMed: 23525196]

Nayeem MA, Poloyac SM, Falck JR, Zeldin DC, Ledent C, Ponnoth DS, Ansari HR, Mustafa SJ, 2008 Role of CYP epoxygenases in A2A AR-mediated relaxation using A2A AR-null and wild-type mice. Am J Physiol Heart Circ Physiol 295, H2068-2078. [PubMed: 18805895]

Nguyen Dinh Cat A, Touyz RM, 2011 Cell signaling of angiotensin II on vascular tone: novel mechanisms. Current hypertension reports 13, 122-128. [PubMed: 21274755]

Nishijima Y, Zheng X, Lund H, Suzuki M, Mattson DL, Zhang DX, 2014 Characterization of blood pressure and endothelial function in TRPV4-deficient mice with 1-NAME- and angiotensin IIinduced hypertension. Physiol Rep 2, e00199. [PubMed: 24744878]

Ohisalo JJ, 1987 Regulatory functions of adenosine. Med.Biol 65, 181-191. [PubMed: 3325699] 
Olanrewaju HA, Mustafa SJ, 2000 Adenosine A(2A) and A(2B) receptors mediated nitric oxide production in coronary artery endothelial cells. Gen Pharmacol 35, 171-177. [PubMed: 11744240]

Olanrewaju HA, Qin W, Feoktistov I, Scemama JL, Mustafa SJ, 2000 Adenosine A(2A) and A(2B) receptors in cultured human and porcine coronary artery endothelial cells. Am J Physiol Heart Circ Physiol 279, H650-656. [PubMed: 10924064]

Özen N, Nasırcılar Ülker S, Ülker P, Özcan F, Aslan M, Şentürk ÜK, Basralı F, 2017 Effect of 20HETE inhibition on L-NAME-induced hypertension in rats. Clinical and Experimental Hypertension, 1-11.

Paulis L, Zicha J, Kunes J, Hojna S, Behuliak M, Celec P, Kojsova S, Pechanova O, Simko F, 2008 Regression of L-NAME-induced hypertension: the role of nitric oxide and endothelium-derived constricting factor. Hypertens Res 31, 793-803. [PubMed: 18633192]

Ponnoth DS, Nayeem MA, Kunduri SS, Tilley SL, Zeldin DC, Ledent C, Mustafa SJ, 2012a Role of omega-hydroxylase in adenosine-mediated aortic response through MAP kinase using A2Areceptor knockout mice. Am J Physiol Regul Integr Comp Physiol 302, R400-408. [PubMed: 22160543]

Ponnoth DS, Nayeem MA, Tilley SL, Ledent C, Jamal Mustafa S, 2012b CYP-epoxygenases contribute to A2A receptor-mediated aortic relaxation via sarcolemmal KATP channels. Am J Physiol Regul Integr Comp Physiol 303, R1003-1010. [PubMed: 23019210]

Pradhan I, Ledent C, Mustafa SJ, Morisseau C, Nayeem MA, 2015 High salt diet modulates vascular response in AAR and A AR mice: role of sEH, PPARgamma, and $\mathrm{K}$ channels. Molecular and cellular biochemistry 5,5 .

Prawez S, Ahanger AA, Singh TU, Mishra SK, Sarkar SN, Kumar D, 2016 BAY 41-2272 Treatment Improves Acetylcholine-Induced Aortic Relaxation in L-NAME Hypertensive Rats. The International journal of angiology : official publication of the International College of Angiology, Inc 25, 235-240.

Sanjani MS, Teng B, Krahn T, Tilley S, Ledent C, Mustafa SJ, 2011 Contributions of A2A and A2B adenosine receptors in coronary flow responses in relation to the KATP channel using A2B and A2A/2B double-knockout mice. Am.J Physiol Heart Circ.Physiol 301, H2322-H2333. [PubMed: 21949117]

Sharifi-Sanjani M, Zhou X, Asano S, Tilley S, Ledent C, Teng B, Dick GM, Mustafa SJ, 2013 Interactions between $\mathrm{A}(2 \mathrm{~A})$ adenosine receptors, hydrogen peroxide, and KATP channels in coronary reactive hyperemia. Am J Physiol Heart Circ Physiol 304, H1294-1301. [PubMed: 23525711]

Sheng J, Xu T, Lin X, Hongmei X, Qi G, Xiaocui D, Yuhong C, Yuming W, 2017 Hydrogen sulfide ameliorated L-NAME-induced hypertensive heart disease by the Akt/eNOS/NO pathway. Experimental biology and medicine 242, 1831-1841. [PubMed: 28971696]

Teng B, Fil D, Tilley SL, Ledent C, Krahn T, Mustafa SJ, 2013 Functional and RNA expression profile of adenosine receptor subtypes in mouse mesenteric arteries. J Cardiovasc Pharmacol 61, 70-76. [PubMed: 23288107]

Tian D, Ling S, Chen G, Li Y, Liu J, Ferid M, Bian K, 2011 Hypertensive nephropathy treatment by heart-protecting musk pill: a study of anti-inflammatory therapy for target organ damage of hypertension. International journal of general medicine 4, 131-139. [PubMed: 21475627]

Wang Y, Zhang F, Liu Y, Yin S, Pang X, Li Z, Wei Z, 2017 Nebivolol alleviates aortic remodeling through eNOS upregulation and inhibition of oxidative stress in l-NAME-induced hypertensive rats. Clinical and Experimental Hypertension 39, 628-639. [PubMed: 28640644]

Yadav VR, Hong KL, Zeldin DC, Nayeem MA, 2016 Vascular endothelial over-expression of soluble epoxide hydrolase (Tie2-sEH) enhances adenosine A1 receptor-dependent contraction in mouse mesenteric arteries: role of ATP-sensitive $\mathrm{K}(+)$ channels. Molecular and cellular biochemistry 422, 197-206. [PubMed: 27629787]

Yadav VR, Nayeem MA, Tilley SL, Mustafa SJ, 2015 Angiotensin II stimulation alters vasomotor response to adenosine in mouse mesenteric artery: role for $\mathrm{A} 1$ and $\mathrm{A} 2 \mathrm{~B}$ adenosine receptors. $\mathrm{Br} \mathrm{J}$ Pharmacol 172, 4959-4969. [PubMed: 26227882] 
Zhou X, Teng B, Tilley S, Mustafa SJ, 2013 A1 adenosine receptor negatively modulates coronary reactive hyperemia via counteracting A2A-mediated $\mathrm{H} 2 \mathrm{O} 2$ production and KATP opening in isolated mouse hearts. Am J Physiol Heart Circ Physiol 305, H1668-1679. [PubMed: 24043252]

Zhou Z, Rajamani U, Labazi H, Tilley SL, Ledent C, Teng B, Mustafa SJ, 2015a Involvement of NADPH oxidase in A2A adenosine receptor-mediated increase in coronary flow in isolated mouse hearts. Purinergic signalling 11, 263-273. [PubMed: 25911169]

Zhou Z, Sun C, Tilley SL, Mustafa SJ, 2015b Mechanisms underlying uridine adenosine tetraphosphate-induced vascular contraction in mouse aorta: Role of thromboxane and purinergic receptors. Vascular pharmacology 

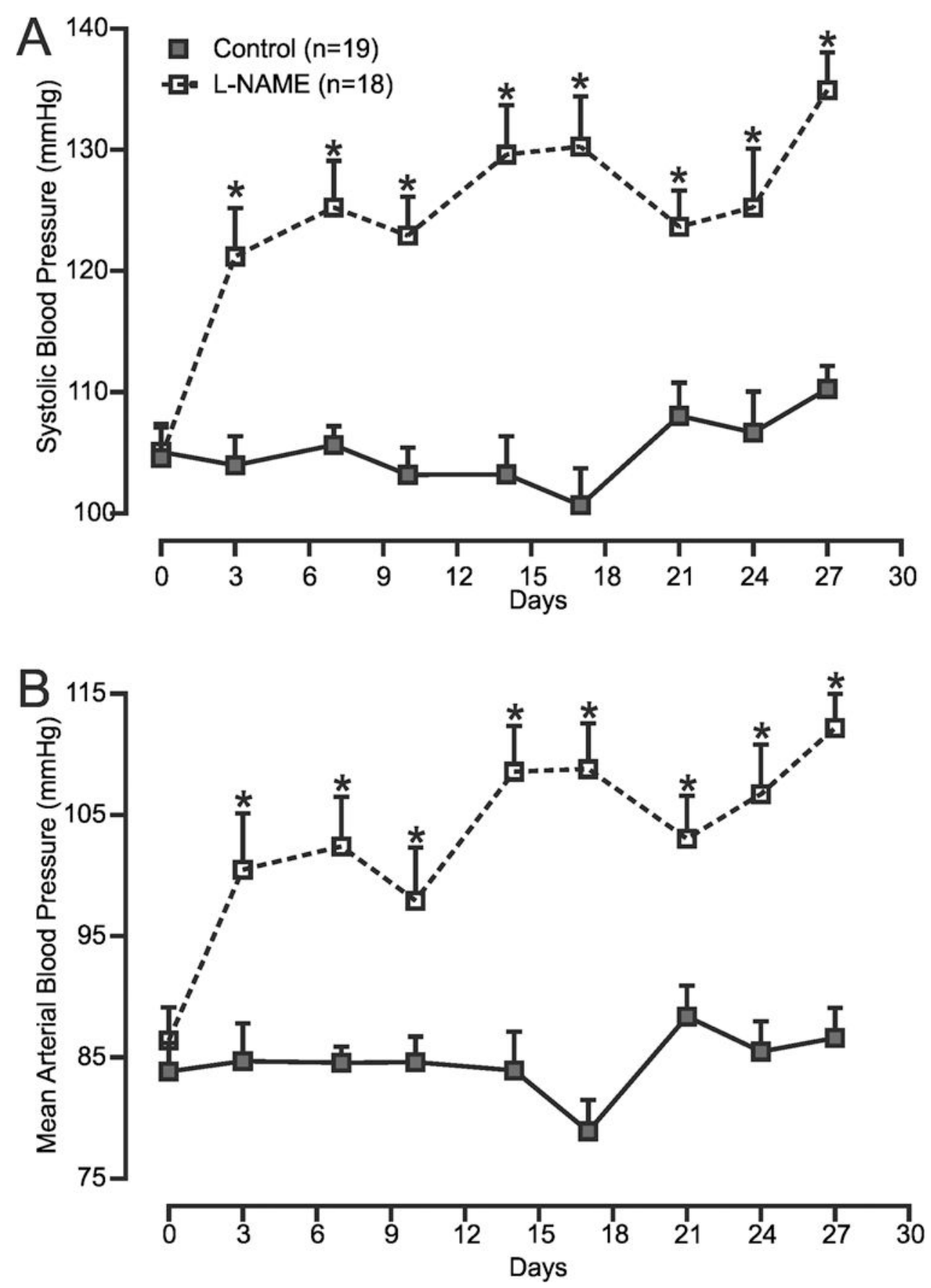

Fig. 1.

L-NAME in drinking water increases BP in mice. Shown are (A) SABP and (B) MABP data recorded from day $0-28 . * \mathrm{P}<0.05$ compared to control at respective day $\mathrm{BP}$. 

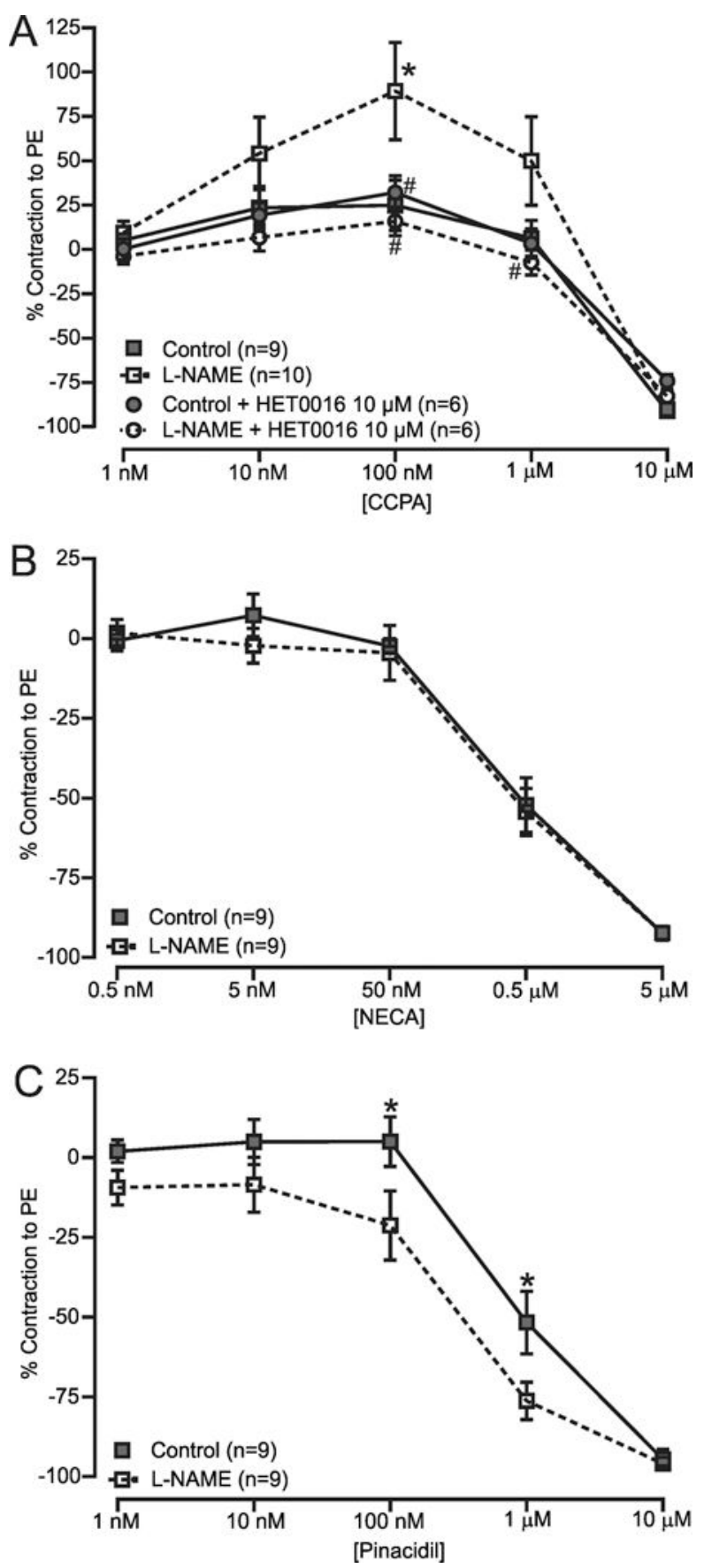

Fig. 2.

Higher $\mathrm{A}_{1} \mathrm{AR}$-induced, CYP4A dependent contraction, and enhanced pinacidil induced relaxations were present in MAs of L-NAME mice. (A) CCPA ( $\mathrm{A}_{1}$ selective agonist)induced contraction response curves (CRCs) and the effect of Cyp4A inhibitor, HET0016 $(10 \mu \mathrm{M})$ on CCPA induced CRCs; (B) NECA and (C) Pinacidil induced CRCs in control and L-NAME mice. * indicates $\mathrm{P}<0.05$ compared to control and \# denotes $\mathrm{P}<0.05$ compared to L-NAME response at a respective concentration. 

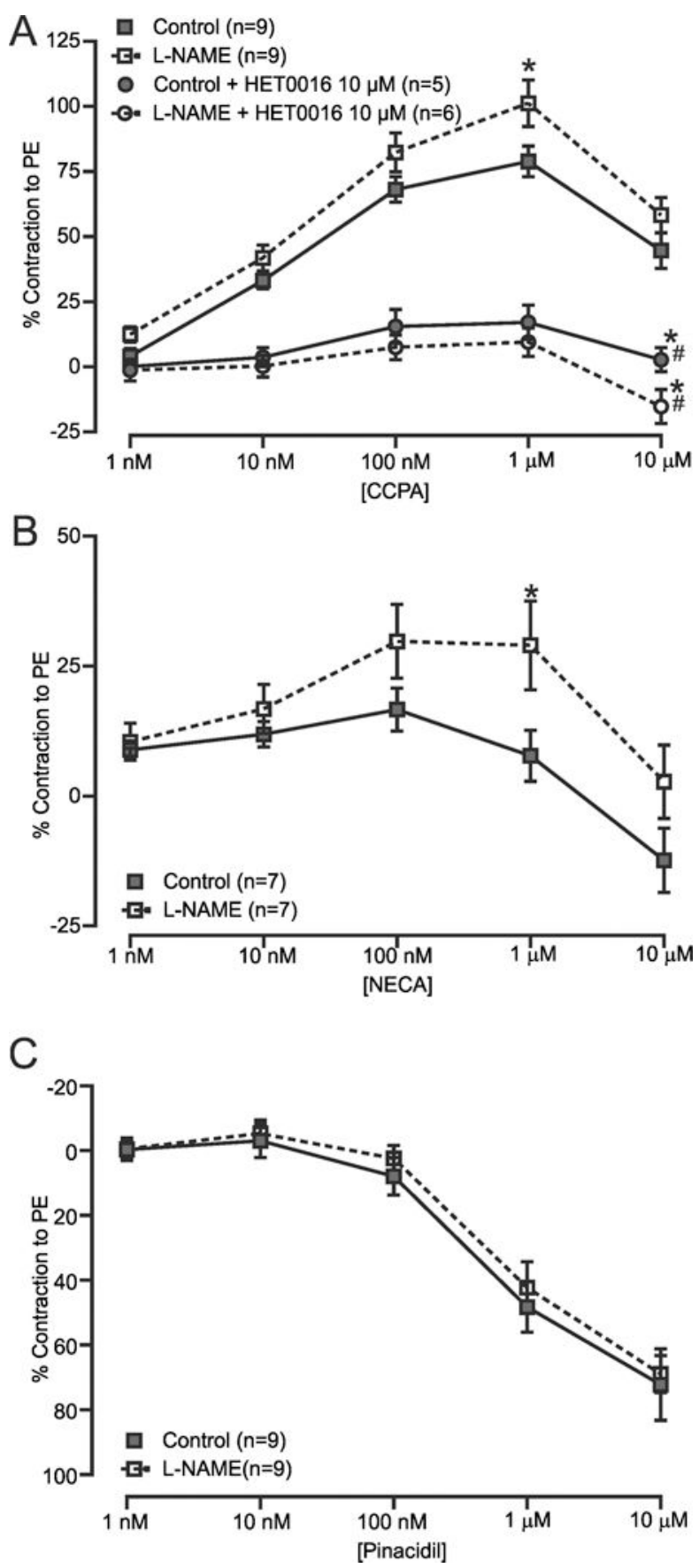

Fig. 3.

$\mathrm{A}_{1} \mathrm{AR}$ induced and Cyp4A dependent higher contractions were observed in aorta of LNAME mice. (A) CCPA and effect of HET0016 on CCPA induced CRCs; (B) NECA; (C) Pinacidil induced CRCs in control and L-NAME mice. * $\mathrm{P}<0.05$ compared to control, \# $\mathrm{P}<0.05$ compared to L-NAME. 


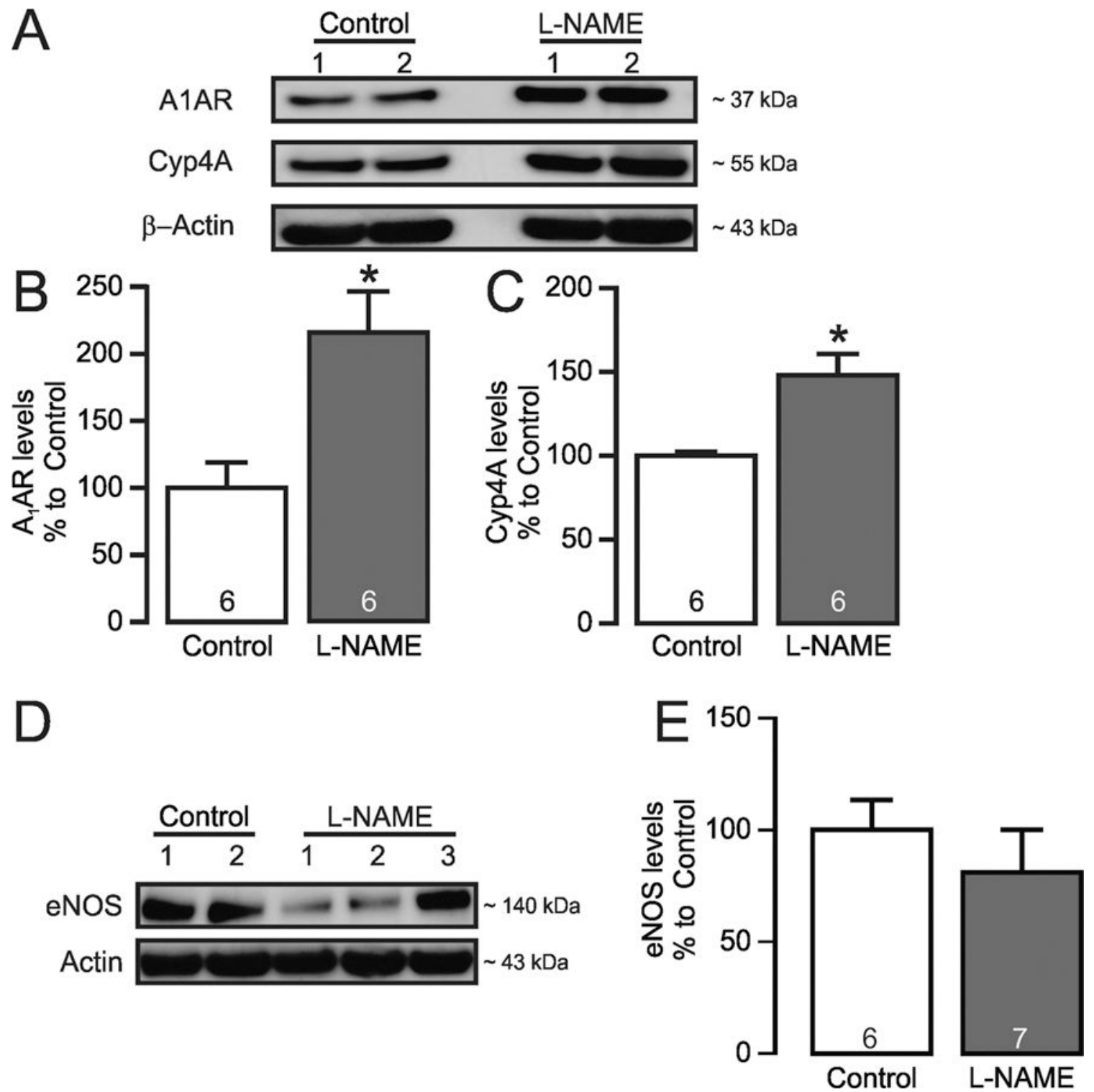

Fig. 4.

Expression levels of $\mathrm{A}_{1} \mathrm{AR}, \mathrm{Cyp} 4 \mathrm{~A}$, and eNOS in MAs of L-NAME hypertensive mice. (A) The panel shows representative western blot of $A_{1} A R$, Cyp4A, and actin from two different mice. Bar graph summarizes quantification of $A_{1} A R(B)$ and Cyp4A (C). (D) Representative blot of eNOS expression from two control and 3 L-NAME mice MAs. (E) Quantification of eNOS levels. $* \mathrm{P}<0.05$ compared to control. The number in the bar graph shows number of animals for the experiment. 

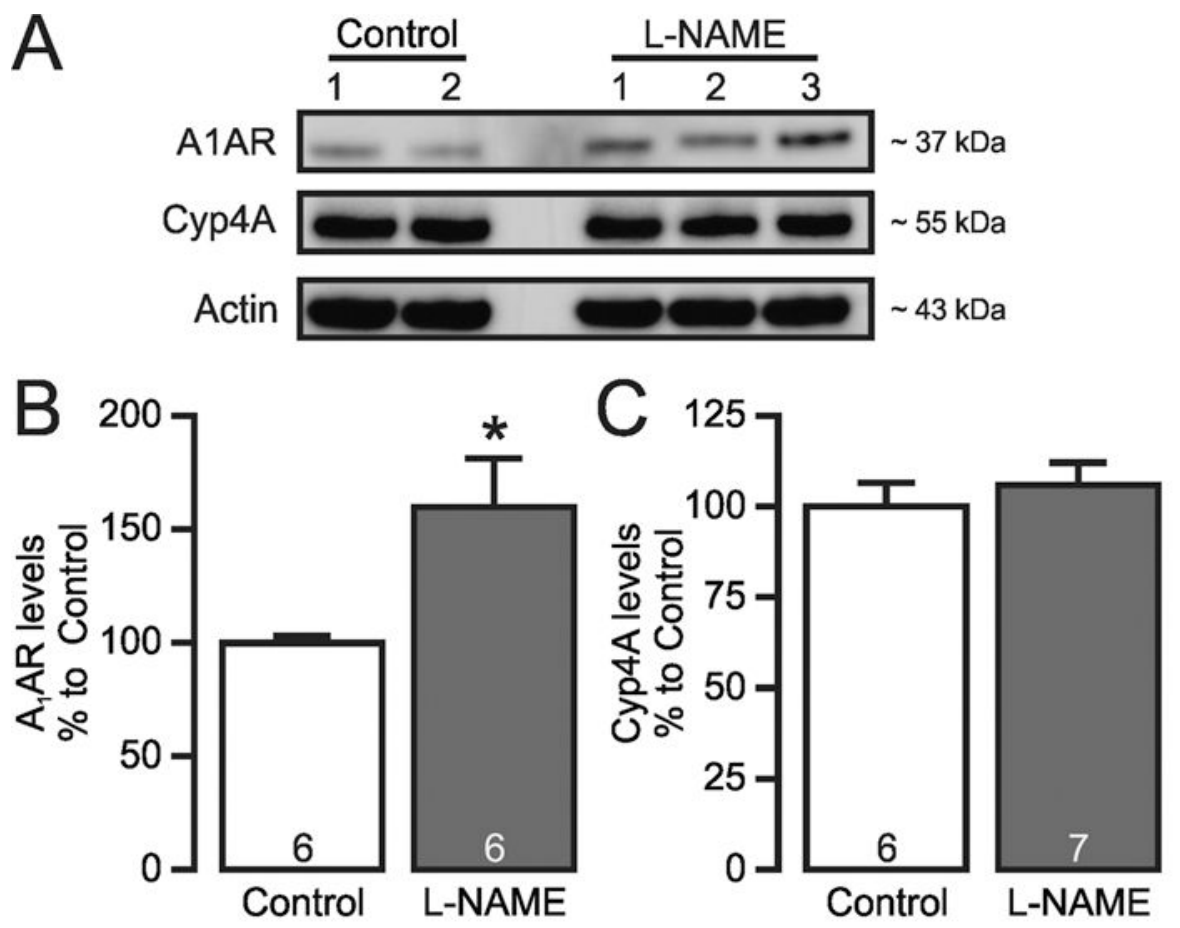

D

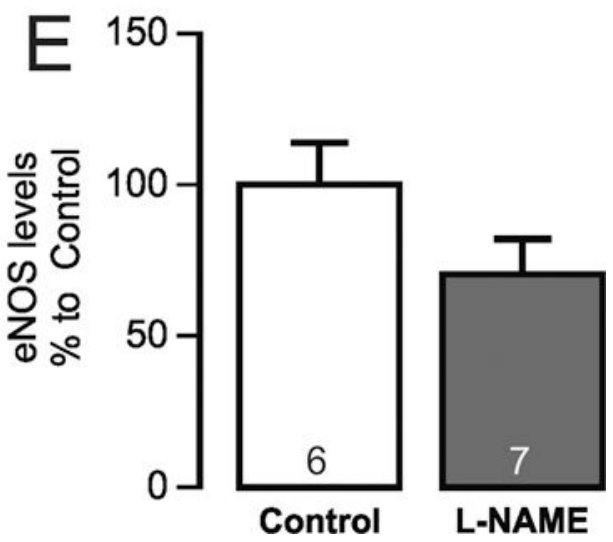

Fig. 5.

Expression levels of $\mathrm{A}_{1} \mathrm{AR}$ and Cyp4A in aorta of L-NAME hypertensive mice. (A) Representative western blot of $\mathrm{A}_{1} \mathrm{AR}$, Cyp4A, and actin from two different mice. Bar graph summarizes quantification of (B) $\mathrm{A}_{1} \mathrm{AR}$ and (C) Cyp4A. (D) Representative blot of eNOS expression from aorta of two control and 3 L-NAME mice. (E) Quantification of eNOS levels. ${ }^{*} \mathrm{P}<0.05$ compared to control. The number in the bar graph shows number of animals for the experiment. 